REVIEW

\title{
Gilles de la Tourette's syndrome and its impact in the UK
}

\author{
J S Stern, S Burza, M M Robertson
}

Postgrad Med J 2005;81:12-19. doi: 10.1136/pgmj.2004.023614

Gilles de la Tourette's syndrome of chronic multiple motor and vocal tics is now acknowledged to be far more common than once thought, affecting up to $1 \%$ of schoolchildren with a wide range of severity. At the milder end of the spectrum the associated psychopathologies can in themselves impair social and educational functioning, in particular obsessive compulsive disorder and attention deficit hyperactivity disorder. Many patients with this condition are not being adequately served by health and education services in the UK. The epidemiology, clinical features, aetiological factors, and management of the syndrome are reviewed.

See end of article for authors' affiliations

Correspondence to: Dr Jeremy Stern, Chairman, Tourette Syndrome (UK) Association, Atkinson Morley's Wing, St George's Hospital, Blackshaw Road, London SW17 OQT, UK; jeremy. stern@stgeorges.nhs.uk

Accepted 28 April 2004
G illes de la Tourette's syndrome (Tourette's syndrome) is a childhood onset inherited neuropsychiatric disorder characterised by the presence of both multiple motor tics and one or more vocal tics (noises), which last longer than a year, the generally accepted research definition being taken from Diagnostic and Statistical Manual of Mental Disorders, 4th edition, text revised (DSM-IV-TR) (see box 1). ${ }^{1}$ This condition is not the rarity once thought, to be pigeon holed in a category of rare and curious psychiatric syndromes, much remembered only by medical students. Along with its common comorbidities it causes a significant impact on quality of life to a significant number of people in the UK, and throughout the rest of the world. This review on the syndrome and its management keeps these points to the fore.

\section{HISTORY}

The first case of Tourette's syndrome in the UK may possibly have been Mary Hall of Gadsden who was reported by William Drage in $1663 .^{2}$ It is now widely accepted that Dr Samuel Johnson had Tourette's syndrome. ${ }^{3}$ Hughlings Jackson documented a patient with Tourette's syndrome in the London Hospital Gazette in 1884, just one year before Dr Georges Gilles de la Tourette reported his cohort of cases which earned him eponymous fame. ${ }^{45}$ The history of Tourette's syndrome as a quintessentially Parisian condition from the School of Charcot has been elegantly reviewed. ${ }^{67}$

\section{CLINICAL FEATURES}

The clinical phenomenology in Tourette's syndrome is uniform, irrespective of the country of origin, with possibly only some minor cultural differences. Thus, motor tics (for example, blinking, mouth pouting, mouth opening, head nodding) and vocal tics (noises, for example, throat clearing, sniffing, coughing) are necessary for the diagnosis to be made, and must be present for a year or more. Coprolalia (the involuntary and inappropriate use of obscenities as a tic) occurs in only about $10 \%$ of all sufferers, despite the media's fascination with this feature. Echophenomena (copying what other people say or do) and palilalia (repetition of what oneself says) are fairly common and very characteristic.

"Non-obscene socially inappropriate" (NOSI) behaviours are increasingly recognised as important to social functioning. Examples include inappropriate personal comments (for example, "Professor Robertson is wearing too much blusher") or a patient who was compelled to shout "bomb" while on an aeroplane. A group of 87 patients with Tourette's syndrome (mean age 28 years) was studied from this perspective. ${ }^{8}$ The reported age at onset of symptoms was 10 years and $48(67 \%)$ were receiving medication. Results showed that $22 \%$ of patients reported behaviours insulting others, other NOSI comments (5\%), and NOSI behaviours (14\%). NOSI behaviour was usually directed at a family member or familiar person at home or in a familiar setting. Social difficulties were commonly reported. NOSI behaviour was closely associated with conduct disorder and attention deficit hyperactivity disorder (ADHD) and it was suggested that NOSI behaviour may represent part of a more general dysfunction of impulse control in Tourette's syndrome. ${ }^{8}$

\section{HOW MANY PEOPLE HAVE TOURETTE'S SYNDROME IN THE UK?}

Two pilot studies followed by definitive studies suggested that Tourette's syndrome was much more common than previously thought, with a ball-park figure of about $1 \%$ of schoolchildren between the ages of 5 and 17 years. ${ }^{9-13}$ This figure of $1 \%$ refers to a condition of wide severity including cases of motor and vocal tics of such mildness to be of no concern to the individual or others. However this may be of educational significance as tic-possible children had much more psychopathology when compared with the whole population (42 of a total of 918) in a study

Abbreviations: $A D H D$, attention deficit hyperactivity disorder; BAD, bipolar affective disorder; DSM-IV-TR, Diagnostic and Statistical Manual of Mental Disorders, 4 th edition, text revised; fMRI, functional magnetic resonance imaging; GABHS, group A $\beta$-haemolytic streptococcal; $\mathrm{NOSI}$, non-obscene socially inappropriate; OCB, obsessive compulsive behaviour; OCD, obsessive compulsive disorder; PANDAS, paediatric autoimmune neuropsychiatric disorders associated with streptococcus; PET, positron emission tomography; SPET, single photon emission tomography 
Box 1: DSM-IV-TR diagnostic criteria for Tourette's syndrome'

(A) Both multiple motor and one or more vocal tics have been present at some time during the illness, although not necessarily concurrently. (A tic is a sudden, rapid, recurrent, non-rhythmic, stereotyped motor movement or vocalisation.)

(B) The tics occur many times a day (usually in bouts) nearly every day or intermittently throughout a period of more than one year, and during this period there was never a tic-free period of more than three consecutive months.

(C) The onset is before age 18 years.

(D) The disturbance is not due to the direct physiological effects of a substance (for example, stimulants) or a general medical condition (for example, Huntington's disease or postviral encephalitis).

in the UK. ${ }^{12}$ In particular they had significantly more probable $\mathrm{ADHD}$, probable conduct disorder, and probable mental disorder. They were also significantly more likely to have had a "statement of special educational needs" and referral to child mental health services. Most of the children in this study had only mild to moderate tic symptoms. The mean Birleson depression score was higher than that of the total population (mean 9, compared with a mean of 4.8 for the total population), indicating that they had depressive symptomatology higher than that of the whole population.

More recently, two large epidemiological studies have been documented with remarkably similar results. Thus in a study of 4479 Swedish schoolchildren aged 7-15 years, 297 were found to have tics. ${ }^{14}$ As many as $0.6 \%$ had symptoms causing distress and impairment from the tics alone. Total tic disorders were found in $6.6 \%$ of children in the year preceding the study, were higher in young children and in males, and were highly associated with social dysfunction. A total of 2347 primary schoolchildren were studied from the city of Pavia (population 80073 ) in Northern Italy, ${ }^{15}$ and 68 children aged 6-11 years were identified with tic disorders. Tourette's syndrome was diagnosed in 16 pupils (24\% of those with tics, and $0.6 \%$ of the total population). The period prevalence of tic disorders was $2.9 \%$ (95\% confidence interval 2.3 to 3.7 ). The prevalence of tics was $4.4 \%$ in boys and $1.1 \%$ in girls. Of importance is that, as encountered in the previous studies cited above, a significant correlation was found between the presence of tic disorders and impaired school performance.

The above recent studies were all fairly similar in that they were undertaken in mainstream schools and employed direct examinations, observations and questionnaires about pupils, as well as obtaining information from parents and teachers. Although there has been debate as to how common Tourette's syndrome is, a prevalence figure of between $0.6 \%$ and $1 \%$ in mainstream schoolchildren (using DSM-IV-TR criteria) is more likely to be correct than the previous lower figures that have been reported. ${ }^{16}$

Tics usually start at the age of around 5 years and in about half tics reduce by the age 18 years. ${ }^{17}$ It may therefore be worthwhile to extrapolate approximate numbers of individuals in the UK who may have Tourette's syndrome. In the UK the current population between the ages of 5-18 years is $10676000 .^{18}$ Thus, with a prevalence of $0.6 \%$ to $1 \%$, this means that between 64000 and 106000 people between the ages of 5 and 18 years in the UK may have Tourette's syndrome, of all severities. The number of adults over the age of 19 years in the UK is 45.19 million. Thus, using Leckman's figure, with a prevalence of $0.3 \%$ to $0.5 \%$, between 135000 and 225000 of them may have Tourette's syndrome. Thus, in the UK as many as 199000 to 331000 individuals may have the syndrome. It is acknowledged that in the majority of these investigations the Tourette's syndrome symptoms are probably mild, fulfilling DSM-IV-TR criteria but unlikely to cause distress or impairment. Nor would they have coprolalia, which only occurs in $10 \%$ of Tourette's syndrome populations overall. They may well, however, have psychopathology or social difficulties as outlined in the epidemiological studies discussed above.

The prevalence of Tourette's syndrome in special educational populations such as those with learning difficulties or autistic spectrum disorder is even higher. ${ }^{9} 3^{19-22}$

These relatively high figures of people with Tourette's syndrome probably apply world wide (apart from subSaharan Africa (Robertson, unpublished), and clearly have wide implications from several points of view including service provision and training, both of medical personnel as well as educators. The problems of educational, social, and medical services in the UK are outside the remit of this article but we suggest that the provision for many thousands of children, parents, and adult patients is not optimal.

\section{PSYCHOPATHOLOGY}

The psychopathology encountered in patients with Tourette's syndrome has been thoroughly documented in two comprehensive reviews. ${ }^{23}{ }^{24}$ Box 2 gives the various types of psychopathology encountered in patients, and the authors' suggestions as to the relationships between Tourette's syndrome and psychopathology.

A large study of 3500 individuals from 22 countries reported that only $12 \%$ of the patients had no comorbidity. ${ }^{25}$ The most common problem reported was ADHD found in $60 \%$, obsessive compulsive behaviour (OCB) in $32 \%$, obsessive compulsive disorder (OCD) in $27 \%$, mood (affective) disorders in $20 \%$, and anxiety disorders in $18 \%$. Conduct disorder and oppositional disorder were found in 15\% of patients.

ADHD or similar symptoms are common in people with Tourette's syndrome, and it seems that they may occur even in mild cases who have been identified in epidemiological studies, such as the study conducted in the Israeli defence services. ${ }^{26}$ The ADHD symptoms are often the difficulties that prompt referral to medical services, and knowledge of them and their treatment is important. A point to emphasise is that although tics may be most outwardly visible, it is these associated psychopathologies that may have most impact on schooling, social and work functioning. ${ }^{27} 28$

$\mathrm{OCD} / \mathrm{OCB}$, as indicated, are common, appear to be genetically integral, and have been well documented in Tourette's syndrome. Several studies have documented significant phenomenological differences between "pure" (primary) OCD and the OCB which has been reported in Tourette's syndrome. In essence, the obsession encountered in patients are to do with sexual, violent, religious, and aggressive themes; the compulsions are to do with checking, ordering, counting, repeating, forced touching, symmetry (evening up), getting things "just right", and self injurious behaviours. In contrast the obsessions in OCD are in the main more likely to be with dirt, germs, and contamination and the resultant compulsions are to do with cleaning and washing. In addition several studies have shown that OCD/OCB may well be phenotypes of the putative Tourette's syndrome gene(s) (for review see Robertson ${ }^{23}$ ).

Self injurious behaviours are found in roughly a third of subjects, but it is of interest that they have also been documented in community cases. ${ }^{29-31}$ In this context, we do 
not mean over-dosing, wrist cutting, or other forms of attempted suicide. The self injurious behaviours encountered in patients with Tourette's syndrome include head banging, body punching, poking sharp objects into the body, and eye injuries. Self injurious behaviour is also related to obsessionality and this factor almost certainly has treatment implications. In fact, symptoms of self injurious behaviour are often difficult to treat.

Affective disorders are also common in people with Tourette's syndrome. Depressive symptomatology and depressive illness both in adults and children has been well documented (for reviews see Robertson ${ }^{23}{ }^{24}$ ). The depression in populations with Tourette's syndrome, as in "primary" depressive illness is highly likely to be multifactorial in origin-that is, partly related to the experience of a chronic socially disabling condition.

Bipolar affective disorder (BAD) has been described in patients with Tourette's syndrome. ${ }^{32}$ Of interest is that a relationship between OCD and BAD has been documented. ${ }^{33}$ In addition, a relationship has been documented between $\mathrm{ADHD}$ and $\mathrm{BAD}$, and also between $\mathrm{BAD}$ and conduct disorder. $^{34} 35$ The authors tentatively suggest that the BAD encountered in patients with Tourette's syndrome may well be due to the comorbidity of BAD with OCD, ADHD and conduct disorder, rather than integral to the Tourette's syndrome per se.

Looking at the question of psychopathology from a different perspective, 200 consecutive adult patients from the wards of a group of north London teaching hospitals were assessed using a standardised schedule for the diagnosis of Tourette's syndrome. ${ }^{36}$ None of the patients had the syndrome, but two were observed to have motor tics. In addition, 10 had a history of tics (but present for less than a year), and seven reported a family history of tics. These findings did not support the theory that Tourette's syndrome and related behaviours are over-represented in adult psychiatric patients.

\section{IMPACT OF TOURETTE'S SYNDROME ON THE PATIENT AND THE FAMILY}

Surprisingly only one study has investigated quality of life in patients with Tourette's syndrome. One hundred and three outpatients with Tourette's syndrome were studied using a semistructured interview and 90 of these also completed questionnaires screening for depression, anxiety, and obsessive compulsive symptoms. Quality of life was measured with the Short Form-36 and the Quality of Life Assessment Schedule. ${ }^{38}$ Other standardised schedules were also employed such as the Beck Depression Inventory, the Leyton Obsessional Inventory, and the State-Trait Anxiety Inventory. Patients with Tourette's syndrome had significantly worse quality of life than the general population, but had better quality of life than 145 patients with intractable epilepsy (undergoing evaluation for neurosurgery), as measured by the Quality of Life Assessment Schedule, although the Short Form-36 showed significant differences on the subscales "role limitation" due to physical problems and "social functioning" only. Factors influencing quality of life domains were employment status, tic severity, OCB, anxiety, and depression.

A cross sectional study over six months compared the mental health and caregiver burden in parents of children with Tourette's syndrome to that of parents of children with asthma. ${ }^{39}$ Main outcome measures were parental mental health (General Health Questionnaire and Child and Adolescent Impact Assessment). Of the parents of children with Tourette's syndrome, $76.9 \%$ achieved scores on the General Health Questionnaire indicative of psychiatric morbidity, compared with $34.6 \%$ of the parents of the children with asthma; this effect remained significant after controlling for
Box 2: Suggested relationships between

psychopathology and Tourette's syndrome

(1) Generally accepted as an integral part of Tourette's syndrome and genetically linked to the syndrome:

- OCD/OCB.

(2) Integral and related to $O C B$ :

- Self injurious behaviours.

(3) Common in Tourette's syndrome and genetically linked in some cases:

- ADHD.

(4) Secondary to having Tourette's syndrome:

- Anxiety disorders.

(5) Multifactorial:

- Depression.

(6) Adult psychopathology as a result of childhood comorbid psychopathology (ADHD, oppositional disorder, conduct disorder) rather than Tourette's syndrome per se:

- Personality disorder.

(7) As a result of referral bias:

- Conduct disorder.

- Oppositional disorder.

- Personality disorder.

(8) Secondary to medication:

- Dysphoria.

- Anxiety (for example, separation anxiety).

- Cognitive impairment.

(9) Result of comorbidity with OCD and ADHD:

- BAD.

(10) More research needed.

- Impulsivity, plus rage but not fulfilling criteria for ADHD.

- Autistic spectrum disorder.

(11) Rare and probably associated by chance:

- Schizophrenia.

Modified from Robertson. ${ }^{24} 37$

demographic variables. Parents of children with Tourette's syndrome also experienced a greater caregiver burden, and this burden was significantly correlated with General Health Questionnaire caseness.

Thus it is clear that both patients with Tourette's syndrome and their parents have difficulties because of the syndrome and management of the patient must be carried out with this in mind.

\section{ASSESSMENT}

Assessment of patients with Tourette's syndrome requires a thorough personal and family history, as well as mental state and neurological examination. There are many standardised rating scales or schedules that help in the more accurate description of symptoms, including the National Hospital Interview Schedule, ${ }^{40}$ the Yale Global Tic Severity Scale, ${ }^{41}$ the Diagnostic Confidence Index, ${ }^{42}$ the MOVES Scale, ${ }^{43}$ the 
Hopkins Motor and Vocal Tic Severity Scale, ${ }^{44}$ and the Tourette's syndrome videotaped scale. ${ }^{45}$ For implementing the majority of these scales, familiarity with Tourette's syndrome, as well as training by an expert, is important. Many of these scales are used in our clinics as they help not only an accurate diagnosis (for example, National Hospital Interview Schedule), but give a likelihood of diagnosis (for example, Diagnostic Confidence Index), indicate severity (for example, Yale Global Tic Severity Scale, MOVES Scale), and can be used in research protocols (for example, Tourette's syndrome videotaped scale). Standardised schedules are mandatory for research and are useful for accurately assessing the response to medication. In terms of clinical diagnosis special investigations are not useful if the assessor is experienced with the syndrome. Although the exclusion of Wilson's disease with serum assay of copper and caeruloplasmin is considered mandatory, in the authors' experience no patient presenting with this distinctive picture of Tourette's syndrome has actually had Wilson's disease and certainly more extensive investigation of copper handling is not necessary.

\section{PATHOGENESIS}

Tourette's syndrome was once thought to be a result of psychological imbalances and the main treatments were consequently psychoanalytical. The cause of Tourette's syndrome remains unknown, although it is undoubtedly an "organic" condition and has been dubbed a model neuropsychiatric syndrome given the reach of its symptoms into both domains. In this section we review what is known and what is hypothesised about the cause of the condition.

\section{(1) Genetics}

Large family pedigrees indicated a genetic element to the disorder and suggested autosomal dominant inheritance. ${ }^{31} 46$ Complex segregation analyses then confirmed that the inheritance pattern was of a single major gene and autosomal dominant. ${ }^{47}$ Much of the genome was, however, excluded and therefore alternatives to a single gene hypothesis have been forwarded including a mixed model, polygenic model, bilineality, and genomic imprinting. ${ }^{48-51}$

Chromosomal abnormalities have always posed an interest in the quest for identifying the gene(s) which are abnormal in Tourette's syndrome. In a cytogenetic investigation embracing 68 patients, the majority (65) had normal karyotypes; the three abnormalities included one patient with an XYY abnormality, and abnormalities of chromosomes of chromosomes 9 and 11, which were suggested to be familial polymorphisms. ${ }^{52}$ Several other chromosomal abnormalities or deletions have been documented; but they do not appear to offer a general message for the majority of patients.

The Tourette Syndrome Association International Genetic Consortium, spearheaded by the American Tourette Syndrome Association (TSA Inc), using sib-pair analysis, undertook the first genome scan in Tourette's syndrome (1999). ${ }^{53}$ The results of that investigation, combined with later studies, suggest regions of interest in the aetiology of the syndrome are on chromosomes 2, 4, 8, and 11. Another study has suggested that the DRD4 and MOA-A genes may confer an increased risk for developing Tourette's syndrome in French Canadians (for review see Robertson ${ }^{37}$ ). The most recent genome scan is from the UK, and shows that in a single large pedigree there is some support for linkage to regions of chromosome 5,10 , and $13 . .^{54}$

Thus, in summary, the single major gene theory with autosomal dominant transmission seems no longer tenable. It is probably too simplistic to posit a single disorder to account for Tourette's syndrome, and indeed a major issue in genetic studies is how to establish caseness with regard to the presence of the various psychopathologies versus tics alone as defined by the diagnostic criteria.

\section{(2) Neuroimmunology: PANDAS}

In the USA Swedo's group described a group of 50 children with OCD and tic disorders, whom they designated as having paediatric autoimmune neuropsychiatric disorders associated with streptococcus (PANDAS) with evidence of group A $\beta$-haemolytic streptococcal (GABHS) infections. ${ }^{55}$ The diagnostic criteria included presence of OCD and/or a tic disorder, prepubertal symptom onset (usually acute and dramatic), association with GABHS infections, episodic course of symptom severity, and association with neurological abnormalities.

This entity therefore serves as an analogy with Sydenham's chorea which itself is associated with neuropsychiatric features. While this area has remained controversial it has been strengthened in the last few years. Antibodies against human basal ganglia tissue have been identified in association with PANDAS and Sydenham's chorea (and cases of sporadic encephalitis lethargica) and cohorts of children with Tourette's syndrome have been screened for streptococcal throat infection and basal ganglia antibodies. These issues have been well demonstrated in a recent UK study of 50 children and 50 adults. ${ }^{56}$ The antistreptolysin-O titre (serological evidence of recent GABHS infection) was raised in $64 \%$ of children and $68 \%$ of adults compared with $15 \%$ or fewer in neurological controls. Furthermore western immunblotting for basal ganglia antibodies was positive in $20 \%$ of children and $27 \%$ of adults with Tourette's syndrome compared with $2 \%-4 \%$ in controls. A $60 \mathrm{kDA}$ basal ganglia antigen has been identified which seems similar to an antigen proposed in the context of Sydenham's chorea. In these patients with basal ganglia antibodies, $91 \%$ had a raised antistreptolysin-O titre compared with $57 \%$ of those without antibodies. ${ }^{56}$

These findings have led to inevitable difficulties in the current era of patients and parents who research the internet. General practitioners and specialists are being asked to screen for GABHS infections and to prescribe antibiotics. The former can't be considered useful in routine clinical practice, given the high carriage rate, and the latter treatment shouldn't really be applicable outside trials. Other immune modulatory strategies including intravenous immunoglobulins and plasmapheresis have been used in small numbers of cases in the USA.

\section{(3) Prenatal and perinatal difficulties}

A potential role of prenatal and perinatal events in the pathogenesis of Tourette's syndrome has also been explored. ${ }^{57}$ As early as 1956 mothers of children with tics were found to be 1.5 times as likely to have experienced a complication during pregnancy than the mothers of children who did not have tics. ${ }^{58}$ Two studies showed that among monozygotic twins discordant for Tourette's syndrome, the index twins with the syndrome always had lower birth weights than their unaffected twins. The severity of maternal life stress during pregnancy and severe nausea and/or vomiting during the first trimester have also been suggested to be risk factors for developing tic disorders. ${ }^{59}$ Other studies showed that premature low birthweight children as well as those with low Apgar scores and more frequent maternal prenatal visits were associated with having Tourette's syndrome. ${ }^{57}$ The present authors' own group reported that possible birth complications occurred in 13/53 patients (induced labour $=3$, umbilical cord round the neck $=3$, neonatal jaundice $=2$, caesarean $\operatorname{section}=2$, forceps delivery $=2$, prolonged labour $=1$, prematurity $=1$, and twin sibling dying at birth $=1$ ). Thus it certainly seems that prenatal and perinatal events have some 
role in the development of Tourette's syndrome, but to date no prospective studies investigating this have been reported.

\section{NEUROIMAGING}

Individual brain scans are in general normal, although there are case reports of various abnormalities. On a research level there have been three types of investigation undertaken in series of patients: volumetric structural imaging and functional imaging of regional metabolism/blood flow using positron emission tomography (PET), single photon emission tomography (SPET) and functional magnetic resonance imaging (fMRI), and lastly regional analyses of neurochemical/receptor activity using ligand PET or SPET.

Imaging may have the potential to offer important insights, as the very few postmortem examinations that have been completed to date have not revealed any definitive neuropathological abnormality.

Volumetric MRI studies have identified changes in volume of the ventricles, basal ganglia, and corpus callosum but some of these data have been conflicting-for example, results indicating a decrease or increase in callosal area. ${ }^{6061}$ If a theme has emerged it is probably the loss of the normal asymmetry of deep brain structures in which most individuals have a slight left sided volume predominance. ${ }^{62}$ An interesting study of affected monozygotic twins discordant for tic severity showed a $6 \%$ reduction in right caudate size in the more severely affected twins; to complicate matters there was also a trend for reduction in size of the left caudate. ${ }^{63}$ Given the confirmed monozygosity in this study, differences could only be environmental.

At first sight the opportunity of functional imaging is appealing but it comes with an immediate difficulty in interpretation-whether changes are attributable to the trait of underlying Tourette's syndrome or should instead be associated with the state of tic performance, or indeed tic suppression. Studies using fMRI and measures of regional cerebral blood flow or glucose metabolism using PET or SPET are littered with this problem, often not acknowledged, which may account for disparate results. Indeed, an fMRI study specifically examining the state of tic suppression showed significant changes in the basal ganglia, thalamus and thalamocortical projections, reproducing the networks seen in some of the other studies of patients not explicitly suppressing their symptoms while in the scanner. ${ }^{64}$ We purposefully neglect to list here the catalogue of studies reporting abnormalities in these regions but do direct the reader to a study using 18F-fluorodeoxyglucose PET (allowing measurement of glucose metabolism) and analysed using covariation of anatomically connected areas, a technique that focuses on networks rather than focal areas. ${ }^{65}$ Two patterns of covariation identified were bilateral increases in lateral premotor, supplementary motor cortices and midbrain and decreases in caudate, thalamus, lentiform, and hippocampus. The former was interpreted as a non-specific network common to hyperkinetic movement disorders and the latter as a more specific limbic basal ganglia-thalamocortical projection system in Tourette's syndrome.

Given the therapeutic efficacy of neuroleptic agents there has been a longstanding focus on dopamine as a central mediator in the condition. Most PET studies have not revealed the relevance of this hypothesis with, for instance, normal presynaptic and postsynaptic dopaminergic binding in the basal ganglia. ${ }^{66}$ However there have been some positive findings: for instance a recent study showing increased dopamine transporter binding ${ }^{67}$ and another study of affected monozygotic twins discordant for severity showing higher dopamine binding in the right caudate in the more severely affected twin. ${ }^{6}$
In summary, Tourette's syndrome is a genetically based condition with environmental influences in which on the basis of therapeutics and some imaging (and other biochemical) evidence dopamine would appear to be important. This does not exclude other neurotransmitters and serotonin and the opioids have also been suggested to be important. Anatomically a hypothesis of basal ganglia involvement is based on little additional data and in fact cingulate/ orbitofrontal circuitry has also been discussed. ${ }^{69}$

The lack of hard conclusions on aetiology reflects a condition with no known microsopic neuropathology in which the genetics have not been amenable to the early identification of a contributing gene.

\section{PROGNOSIS}

The condition is thought of as lifelong and tends to vary in severity over time in individuals. Surprisingly little hard evidence is available to advise patients how things might change over life but there is an impression of improvement at or after adolescence and also in older age. A longitudinal study of 36 children up the age of 18 showed that half were almost tic-free by that stage. ${ }^{17}$ It is self evident that patients seen in specialist clinics after this age represent an obvious form of referral bias and there are clearly also individuals who suffer very greatly throughout their lives.

While diagnostic criteria define Tourette's syndrome as starting before the age of 18, adult onset cases are also documented. They tend to be more associated with severe symptoms and a potential trigger event. ${ }^{70}$

\section{MANAGEMENT AND TREATMENT}

The complexities of treatment have been reviewed..$^{23} 71$ Reassurance, explanation, supportive psychotherapy, and psychoeducation are important and ideally the treatment should be multidisciplinary. In mild cases the previous methods may be all that is required, supplemented with contact with the Tourette Syndrome Association (http:// www.tsa.org.uk) where the patient or parents wish. The association can provide information, support, and advocacy. If the self esteem is low, psychotherapy or individual/group social skills training may be useful. If rage/anger attacks are present anger management may be helpful.

The importance of increasing knowledge about Tourette's syndrome among educationists cannot be overemphasised. ${ }^{72}$ Many pupils have difficulties at school and in many instances a "statement of special educational needs" may be needed. For doctors to be involved in a statementing process, it is essential they are acquainted with Tourette's syndrome and have the knowledge on how to orchestrate the statementing process, giving the appropriate medical support. This may well improve the pupil's chances to obtain a better education and thus improve their life chances.

\section{PSYCHOBEHAVIOURAL MANAGEMENT}

A recent review discusses in detail the psychobehavioural management of patients with Tourette's syndrome. ${ }^{73}$ Psychobehavioural therapies are shown in the box 3 .

The two most successful therapies in patients with Tourette's syndrome are without doubt cognitive behavioural therapy and habit reversal training. Cognitive behavioural therapy has long been described as successful in OCD patients for many years. ${ }^{75}$ In Tourette's syndrome it is acknowledged that the best option for children may well be cognitive behavioural therapy alone, but a combination of cognitive behavioural therapy, a selective serotonin reuptake inhibitor, and a small dose of neuroleptic may well be the best option. Habit reversal training is gaining momentum as a behavioural treatment for Tourette's syndrome. Habit reversal training consists of eight primary intervention 


\section{Box 3: Psychobehavioural therapies}

- Psychotherapy.

- Hypnotherapy.

- Massed negative practice.

- Brief behaviour therapy.

- Assertiveness training.

- Self monitoring.

- Social skill group.

- Cognitive behavioural therapy.

- Habit reversal training.

Modified from Robertson ${ }^{74}$

components; these include four awareness training components (for example, response description, response detection, an early warning procedure, and situation awareness training), competing response practice, as well as motivation/ ancillary techniques, and finally the use of strategies to maintain and generalise treatment gains to multiple settings. $^{73}$ The first randomised controlled study of habit reversal training compared it to supportive psychotherapy in 32 patients with Tourette's syndrome. Standardised rating scales and schedules were employed to measure outcome. ${ }^{76}$ Results showed that the 16 patients receiving habit reversal training improved significantly better than the 13 patients in the supportive psychotherapy group at 10 month follow up. This study is the culmination of many smaller but well described studies and it may well be the way ahead for noninvasive successful treatment of patients without the many side effects which are encountered with almost any medication currently available.

\section{MEDICATION}

The mainstay of drug treatment has been neuroleptics, with the index drug being haloperidol, which suppresses tics. Drug treatment needs to be directed on a symptom based approach and so comorbid depression, OCD, and ADHD must be addressed (table 1). An agent useful for both tics and hyperactivity and traditionally more used in the USA is the $\alpha_{2}$-noradrenergic agonist clonidine. ${ }^{77}$ The standard treatment for ADHD, monoamine stimulants like methylphenidate have been controversial in Tourette's syndrome, as the notion that tics may become more severe has to be considered. In practice now many clinicians are comfortable with the combination, particularly after evidence from a multicentre double blind trial. $^{78}$ As implied above the decision to initiate drug

Table 1 Medication for Tourette's syndrome

\begin{tabular}{lll}
\hline Tics & Neuroleptics & $\begin{array}{l}\text { Haloperidol, sulpiride, } \\
\text { pimozide } \\
\text { Risperidone, olanzepine, } \\
\text { quetiapine } \\
\text { Clonidine }\end{array}$ \\
Atypical agents & Others & $\begin{array}{l}\text { Fluoxetine, citalopram, } \\
\text { fluvoxamine, paroxetine }\end{array}$ \\
ADHD & SSRls & $\begin{array}{l}\text { Methylphenidate, } \\
\text { pemoline, } \\
\text { dextroamphetamine } \\
\text { Clonidine }\end{array}$ \\
\hline
\end{tabular}

$A D H D$, attention deficit hyperactivity disorder; $O C D$, obsessive compulsive disorder; SSRIs, selective serotonin reuptake inhibitors. treatment will depend on several factors including the distress and dysfunction caused by the disorder. There are a number of quite severely affected patients who prefer to stay off treatment, illustrating the nature of a condition that can be integral to personality.

Trials in this area are exceedingly difficult to conduct. Severity of symptoms is hard to objectively rate (although there are several rating scales, see above) and they naturally wax and wane, as does the response to a particular treatment over time. The best literature to date has provided double blind crossover studies of haloperidol and pimozide demonstrating equivalent efficacy but superior adverse affect profile of pimozide.$^{80}$ Most recently risperidone has been compared with pimozide in a similar rigorous design and risperidone was found to be superior but associated with weight gain. ${ }^{81}$

Below this level of evidence the literature is scattered with case reports and small series, sometimes placebo controlled, of a variety of agents from other classes; these should probably be considered experimental and we will cite a small selection of interest. Nicotine, administered as a patch or gum, has been proposed to "augment" the effect of neuroleptics, confirmed in a double blind study, and might be useful on a "as required" basis. ${ }^{82}$ Tetrabenazine has been found helpful in a retrospective series, but a drawback might be the depression it can induce. ${ }^{83}$ A surprising effect of botulinum toxin has been to have more widespread effects than the focal relief one might expect. Vocal cord injections have been successful for vocal tics and coprolalia. ${ }^{84}$ The studies probably exciting the most interest among adult patients are those concerning cannabinoids as some subjects have reported marijuana to be helpful. ${ }^{86}$ This account is necessarily brief and selective and has not touched on the issue of adverse effects, which is of great importance in children; readers are directed to full reviews of the topic. ${ }^{23} 71$

A particularly challenging scenario is the treatment of the patient with severe self injurious behaviours. Treatment options include neuroleptics directed at tics and selective serotonin reuptake inhibitors targeting the obsessional components of the phenomena. Rarely psychosurgery is employed-for example, limbic leucotomy.$^{87} \mathrm{~A}$ number of procedures have been used, for severe Tourette's syndrome in general, sometimes with sketchy documentation in the literature and sometimes including paediatric subjects. ${ }^{88} \mathrm{It}$

\section{Key references}

- Robertson MM. Tourette syndrome, associated conditions and the complexities of treatment. Brain 2000; 123(pt 3):425-62.

- Robertson MM. Heterogenous psychopathology of Tourette syndrome. In: Bedard M, Agid Y, Chouinard $S$, et al, eds. Mental and behavioural dysfunction in movement disorders. Totawa, NJ: Humana Press, 2003:443-66.

- Tourette Syndrome Association International Consortium for Genetics. A complete genome scan in sib-pairs affected with Gilles de la Tourette syndrome. Am J Hum Genet 1999;65:1428-36.

- Wilhelm S, Deckersbach T, Coffey BJ, et al. Habit reversal versus supportive psychotherapy for Tourette's disorder: a randomized controlled trial. Am J Psychiatry 2003;160:1175-7.

- Khalifa N, von Knorring AL. Prevalence of tic disorders and Tourette syndrome in a Swedish school population. Dev Med Child Neurol 2003;45:315-9. 
is quite clear that no such operations should be performed for tics without the participation of a medical ethics committee. A new development is the trial of deep brain procedures which have been found successful in Parkinson's disease (for example, deep brain stimulation). This may well prove more interesting than the traditional psychosurgery procedures.

From the authors' personal experience of drug treatment in "standard" cases, we would recommend sulpiride as a first line agent for tics in adults and clonidine or sulpiride in young people. Sometimes polytherapy is necessary particularly with comorbidities. Although risperidone is supported by the literature we have found it ineffective for tics in adults, however it seems useful for behavioural disturbances in children. For ADHD methylphenidate is very useful and if the tics do increase one could add a small dose of sulpiride. For OCD we start with a selective serotonin reuptake inhibitor. As paroxetine is no longer used in children fluoxetine is probably the drug of choice. If possible behavioural therapies should be used as an adjunct.

\section{CONCLUSIONS}

Recent studies indicate that Tourette's syndrome is a relatively common disorder in mainstream schools $(0.6 \%$ to $1 \%$ ) and it is usually inherited, with OCB/OCD being phenotypes of the putative gene(s). The major current handicaps for the community of people affected by the syndrome in the UK are delayed diagnosis, non-specialist management, and inadequate educational support. Psychopathology is common and includes OCD/OCB, ADHD, depression, BAD, and other behavioural difficulties. Some of the psychopathologies may be integral (for example, OCD/ OCB), whereas others (for example, personality disorder in adults) may be due to other conditions (for example, ADHD, conduct disorder) rather than the Tourette's syndrome per se. Treatment is important as it alleviates suffering, embarrassment, and may improve prognosis in terms of tics and psychopathology and resultant quality of life. Treatment should be symptom targeted, but must be holistic.

\section{QUESTIONS (TRUE (T)/FALSE (F); ANSWERS AT END OF REFERENCES)}

1. The prevalence of Tourette's syndrome is approximately $1: 10000$

2. Tourette's syndrome is associated with macroscopic right caudate atrophy

3. Tourette's syndrome is familial

4. Depression in Tourette's syndrome is likely to be genetically determined

5. There is positive evidence for the use of behavioural treatments

6. Tics can be treated with dopamine antagonists

7. Stimulants (for example, methylphenidate) exacerbate tics and are contraindicated

\footnotetext{
Authors' affiliations

J S Stern, Atkinson Morley's Wing, St George's Hospital, London, UK S Burza, North London Rotation, Camden and Islington Mental Health Trust, London, UK

M M Robertson, Department of Mental Health Sciences, University College London, and St George's Hospital Medical School, London, UK

\section{REFERENCES}

1 American Psychiatric Association. Diagnostic and statistical manual of mental disorders, 4th Ed, text revised (DSM-IV-TR). Washington, DC: American Psychiatric Association, 2000.
}

2 Lees AJ, Robertson M, Trimble MR, et al. A clinical study of Gilles de la Tourette syndrome in the United Kingdom. I Neurol Neurosurg Psychiatry 1984;47:1-8

3 Murray TJ. Dr Samuel Johnson's movement disorder. BMJ 1979;ii:1610-14.

4 Hughlings Jackson J. Clinical lectures and reports to the London Hospital $1884 ; 1: 452$.

5 Gilles de la Tourette G. Etude sure une affection nerveuse caraterisee par de l'incoordination motrice accompagnee d'echolalie et de coprolalie. Archives de Neurologie 1885;9:19-42.

6 Lees AJ. Georges Gilles de la Tourette. The man and his times. Rev Neurol (Paris) 1986; 142:808-16.

7 Kushner HI, Luzzatti C, Finger S. A perplexing document in the early history of Gilles de la Tourette Syndrome: Melotti's rendition of a "Lecture of Charcot" (including a complete translation from the Italian with commentary). Journal of the History of the Neurosciences 1999;8:5-20.

8 Kurlan R, Daragjati C, Como PG, et al. Non-obscene complex socially inappropriate behavior in Tourette's syndrome. J Neuropsychiatry Clin Neurosci 1996:8:311-7.

9 Kurlan R, Whitmore D, Irvine C, et al. Tourette's syndrome in a special education population: a pilot study involving a single school district. Neurology 1994;44:699-702

10 Mason A, Banerjee S, Eapen V, et al. The prevalence of Tourette syndrome in a mainstream school population. Dev Med Child Neurol 1998;40:292-6.

11 Kadesjo B, Gillberg C. Tourette's disorder: epidemiology and comorbidity in primary school children. J Am Acad Child Adolesc Psychiatry 2000;39:548-55.

12 Hornsey $\mathrm{H}$, Banerjee S, Zeitlin $\mathrm{H}$, et al. The prevalence of Tourette syndrome in 13-14-year-olds in mainstream schools. J Child Psychol Psychiatry 2001;42:1035-9.

13 Kurlan R, Mcdermott MP, Deeley C, et al. Prevalence of tic in school children and association with placement in special education. Neurology 2001;57:1383-8.

14 Khalifa N, von Knorring AL. Prevalence of tic disorders and Tourette syndrome in a Swedish school population. Dev Med Child Neurol 2003;45:315-9.

15 Lanzi G, Zambrino CA, Termine C, et al. Prevalence of tic disorders among primary school students in the city of Pavia, Italy. Arch Dis Child 2004 (in press).

16 Scahill L, Tanner C, Dure L. The epidemiology of tics and Tourette syndrome in children and adolescents. Adv Neurol 2001;85:261-71.

17 Leckman JF, Zhang H, Vitale A, et al. Course of tic severity in Tourette syndrome: the first two decades. Pediatrics 1998;102(1 pt 1):14-9.

18 National Statistics Library and Information Service. Newport: 2000 (personal communication). Available at: www.statistics.gov.uk/services/ NSlibraryServices.asp.

19 Eapen V, Robertson MM, Zeitlin H, et al. Gilles de la Tourette's syndrome in special education schools: a United Kingdom study. J Neurol 1997;244:378-82

20 Baron-Cohen S, Mortimore C, Moriarty J, et al. The prevalence of Gilles de la Tourette's syndrome in children and adolescents with autism. J Child Psychol Psychiatry 1999;40:213-8.

21 Baron-Cohen S, Scahill VL, Izaguirre J, et al. The prevalence of Gilles de la Tourette syndrome in children and adolescents with autism: a large scale study. Psychol Med 1999;29:1151-9.

22 Stern JS, Robertson MM. Tics associated with autistic and pervasive developmental disorders. In: Jankovic J, ed. Tourette syndrome. Philadelphia: W B Saunders, 1997:345-55.

23 Robertson MM. Tourette syndrome, associated conditions and the complexities of treatment. Brain 2000;123(pt 3):425-62.

24 Robertson MM. Heterogenous psychopathology of Tourette syndrome. In: Bedard M, Agid Y, Chouinard S, et al, eds. Mental and behavioural dysfunction in movement disorders. Totawa, NJ: Humana Press, 2003:443-66.

25 Freeman RD, Fast DK, Burd L, et al. An international perspective on Tourette syndrome: selected findings from 3,500 individuals in 22 countries. Dev Med Child Neurol 2000;42:436-47.

26 Apter A, Pauls DL, Bleich A, et al. An epidemiologic study of Gilles de la Tourette's syndrome in Israel. Arch Gen Psychiatry 1993;50:734-8.

27 Comings DE, Comings BG. A controlled study of Tourette syndrome. I. Attention-deficit disorder, learning disorders, and school problems. Am J Hum Genet 1987;41:701-41

28 Abwender DA, Como PG, Kurlan R, et al. School problems in Tourette's syndrome. Arch Neurol 1996;53:509-11.

29 Robertson MM, Trimble MR, Lees AJ. Self-injurious behaviour and the Gilles de la Tourette syndrome: a clinical study and review of the literature. Psychol Med 1989;19:611-25.

30 Caine ED, McBride MC, Chiverton P, et al. Tourette's syndrome in Monroe County school children. Neurology 1988;38:472-5.

31 Robertson MM, Gourdie A. Familial Tourette's syndrome in a large British pedigree. Associated psychopathology, severity, and potential for linkage analysis. Br J Psychiatry 1990;156:515-21.

32 Berthier ML, Kulisevsky J, Campos VM. Bipolar disorder in adult patients with Tourette's syndrome: a clinical study. Biol Psychiatry 1998;43:364-70.

33 Hantouche EG, Kockman F, Demonfaucon C, et al. Bipolar obsessivecompulsive disorder: confirmation of results of the "ABC-OCD" survey in 2 populations of patient members versus non-members of an association. Encephale 2002;28:21-8.

34 Wilens TE, Biederman J, Wozniak J, et al. Can adults with attention-deficit/ hyperactivity disorder be distinguished from those with comorbid bipolar disorder? Findings from a sample of clinically referred adults. Biol Psychiatry 2003;54:1-8. 
35 Biederman J, Mick E, Wozniak J, et al. Can a subtype of conduct disorder linked to bipolar disorder be identified? Integration of findings from the Massachusetts General Hospital Pediatric Pyschopharmacology Research Program. Biol Psychiatry 2003;53:952-60.

36 Eapen V, Laker M, Anfield A, et al. Prevalence of tics and Tourette syndrome in an inpatient adult psychiatry setting. J Psychiatry Neurosci $2001 ; 26: 417-20$.

37 Robertson MM. Tourette's syndrome: an update. Psychiatry 2004 (in press)

38 Elstner K, Selai CE, Trimble MR, et al. Quality of life (QOL) of patients with Gilles de la Tourette's syndrome. Acta Psychiatr Scand 2001;103:52-9.

39 Cooper C, Robertson MM, Livingston G. Psychological morbidity and caregiver burden in parents of children with Tourette's disorder and psychiatric comorbidity. J Am Acad Child Adolesc Psychiatry 2003:42:1370-5.

40 Robertson MM, Eapen V. The National Hospital Interview Schedule for the asessment of Gilles de la Tourette syndrome. International Journal of Methods in Psychiatric Research 1996:6.

41 Leckman J, Riddle M, Harden M. The Yale global tic severity scale: initial testing of a clinician-rated scale of tic severity. J Am Acad Child Adolesc Psychiatry 1989;28:566-73.

42 Robertson MM, Banerjee S, Kurlan R, et al. The Tourette syndrome diagnostic confidence index: development and clinical associations. Neurology 1999:53:2108-12.

43 Gaffney GR. The MOVES: a self-rating scale for Tourette's syndrome. J Child Adolesc Psychopharmacol 1994;4:269-80.

44 Walkup JT, Rosenberg LA, Brown J, et al. The validity of instruments measuring tic severity in Tourette's syndrome. J Am Acad Child Adolesc Psychiatry 1992;31:472-7.

45 Goetz CG, Tanner CM, Wilson RS, et al. A rating scale for Gilles de la Tourette's syndrome: description, reliability, and validity data. Neurology 1987;37:1542-4

46 Kurlan R, Behr J, Medved L, et al. Familial Tourette's syndrome: report of a large pedigree and potential for linkage analysis. Neurology 1986;36:772-6.

47 Curtis D, Robertson MM, Gurling HM. Autosomal dominant gene transmission in a large kindred with Gilles de la Tourette syndrome. Br J Psychiatry 1992;160:845-9

48 Walkup JT, LaBuda MC, Singer HS, et al. Family study and segregation analysis of Tourette syndrome: evidence for a mixed model of inheritance. Am J Hum Genet 1996;59:684-93.

49 Comings DE, Wu S, Chiu C, et al. Polygenic inheritance of Tourette syndrome, stuttering, attention deficit hyperactivity, conduct, and oppositional defiant disorder: the additive and subtractive effect of the three dopaminergic genes-DRD2, D beta H, and DAT1. Am J Med Genet 1996;67:264-88.

50 Kurlan R, Eapen V, Stern J, et al. Bilineal transmission in Tourette's syndrome families. Neurology 1994;44:2336-42.

51 Eapen V, O'Neill J, Gurling HM, et al. Sex of parent transmission effect in Tourette's syndrome: evidence for earlier age at onset in maternally transmitted cases suggests a genomic imprinting effect. Neurology 1997;48:934-7.

52 Robertson MM, Trimble MR. Normal chromosomal findings in Gilles de la Tourette syndrome. Psychiatr Genet 1993;3:95-99.

53 Tourette Syndrome Association International Consortium for Genetics. A complete genome scan in sib-pairs affected with Gilles de la Tourette syndrome. Am J Hum Genet 1999;65:1428-36.

54 Curtis D, Brett P, Dearlove OR, et al. Genome scan of Tourette syndrome in a single large pedigree shows some support for linkage to regions of chromosomes 5, 10 and 13. Psychiatr Genet 2004 (in press).

55 Swedo SE, Leonard HL, Garvey M, et al. Pediatric autoimmune neuropsychiatric disorders associated with streptococcal infections: clinical description of the first 50 cases. Am J Psychiatry 1998;155:264-71.

56 Church AJ, Dale RC, Lees AJ, et al. Tourette's syndrome: a cross sectional study to examine the PANDAS hypothesis. J Neurol Neurosurg Psychiatry 2003;74:602-7

57 Leckman JF. In search of the pathophysiology of Tourette syndrome. In: Bedard M, Agid Y, Chouinard S, et al, eds. Mental and behavioral dysfunction in movement disorders. Totowa, NJ: Humana Press, 2003:467-76.

58 Pasamanick B, Kawi A. The study of the association of prenatal and paranatal factors in the development of tics in children. Pediatrics 1956;48:596-601.

59 Leckman JF, Dolnansky ES, Hardin MT, et al. Perinatal factors in the expression of Tourette's syndrome: an exploratory study. J Am Acad Child Adolesc Psychiatry 1990;29:220-6.

60 Peterson BS, Leckman JF, Duncan JS, et al. Corpus callosum morphology from magnetic resonance images in Tourette's syndrome. Psychiatry Res 1994;55:85-99.
61 Moriarty J, Varma AR, Stevens J, et al. A volumetric MRI study of Gilles de la Tourette's syndrome. Neurology 1997;49:410-5.

62 Singer HS, Reiss AL, Brown JE, et al. Volumetric MRI changes in basal ganglia of children with Tourette's syndrome. Neurology 1993:43:950-6.

63 Hyde TM, Stacey ME, Coppola R, et al. Cerebral morphometric abnormalities in Tourette's syndrome: a quantitative MRI study of monozygotic twins. Neurology 1995; $45: 1176-82$

64 Peterson BS, Skudlarski P, Anderson AW, et al. A functional magnetic resonance imaging study of tic suppression in Tourette syndrome. Arch Gen Psychiatry 1998;55:326-33.

65 Eidelberg D, Moeller JR, Antonini A, et al. The metabolic anatomy of Tourette's syndrome. Neurology 1997;48:927-34.

66 Turjanski N, Sawle GV, Playford ED, et al. PET studies of the presynaptic and postsynaptic dopaminergic system in Tourette's syndrome. J Neurol Neurosurg Psychiatry 1994; 57:688-92.

67 Serra-Mestres J, Ring HA, Costa DC, et al. Dopamine transporter binding in Gilles de la Tourette syndrome: a[123I]FP-CIT/SPECT study. Acta Psychiatr Scand 2004;109:140-6.

68 Wolf SS, Jones DW, Knable MB, et al. Tourette syndrome: prediction of phenotypic variation in monozygotic twins by caudate nucleus D2 receptor binding. Science 1996;273:1225-7.

69 Weeks RA, Turjanski N, Brooks DJ. Tourette's syndrome: a disorder of cingulate and orbitofrontal function? Q J Med 1996;89:401-8.

70 Eapen V, Lees AJ, Lakke JP, et al. Adult-onset tic disorders. Mov Disord 2002; 17:735-40.

71 Robertson MM, Stern JS. Gilles de la Tourette syndrome: symptomatic treatment based on evidence. Eur Child Adolesc Psychiatry 2000;9(suppl 1):160-75.

72 Carroll A, Robertson M. Tourette syndrome. A practical guide for teachers, parents and carers. London: David Fulton, 2000.

73 Piacentini J, Chang S. Behavioral treatments for Tourette syndrome and tic disorders: state of the art. Adv Neurol 2001;85:319-31.

74 Robertson MM. Gilles de la Tourette syndrome. The Psychologist 2004;17:76-9.

75 Baxter LR, Schwartz JM, Bergman KS. Caudate glucose metablic rate changes with both drug and behaviour therapy for obsessive-compulsive disorders. Arch Gen Psychiatry 1992;49:681-9.

76 Wilhelm S, Deckersbach T, Coffey BJ, et al. Habit reversal versus supportive psychotherapy for Tourette's disorder: a randomized controlled trial. Am J Psychiatry 2003; 160:1175-7.

77 Leckman JF, Hardin MT, Riddle MA, et al. Clonidine treatment of Gilles de la Tourette's syndrome. Arch Gen Psychiatry 1991;48:324-8.

78 Tourette Syndrome Study Group. Treatment of ADHD in children with tics: a randomized controlled trial. Neurology 2002;58:527-36.

79 Kurlan R. Tourette's syndrome: are stimulants safe? Curr Neurol Neurosci Rep 2003:3:285-8.

80 Sallee FR, Nesbitt L, Jackson C, et al. Relative efficacy of haloperidol and pimozide in children and adolescents with Tourette's disorder. Am J Psychiatry 1997; 154:1057-62.

81 Gilbert DL, Batterson JR, Sethuraman G, et al. Tic reduction with risperidone versus pimozide in a randomized, double-blind, crossover trial. J Am Acad Child Adolesc Psychiatry 2004;43:206-14.

82 Silver AA, Shytle RD, Philipp MK, et al. Transdermal nicotine and haloperidol in Tourette's disorder: a double-blind placebo-controlled study. J Clin Psychiatry $2001 ; 62: 707-14$.

83 Jankovic J, Beach J. Long-term effects of tetrabenazine in hyperkinetic movement disorders. Neurology 1997;48:358-62

84 Porta M, Maggioni G, Ottaviani F, et al. Treatment of phonic tics in patients with Tourette's syndrome using botulinum toxin type A. Neurol Sci 2004;24:420-3.

85 Scott BL, Jankovic J, Donovan DT. Botulinum toxin injection into vocal cord in the treatment of malignant coprolalia associated with Tourette's syndrome. Mov Disord 1996;11:431-3.

86 Muller-Vahl KR. Cannabinoids reduce symptoms of Tourette's syndrome. Expert Opin Pharmacother 2003;4:1717-25.

87 Robertson M, Doran M, Trimble M, et al. The treatment of Gilles de la Tourette syndrome by limbic leucotomy. I Neurol Neurosurg Psychiatry 1990:53:691-4.

88 Rauch SL, Baer L, Cosgrove GR, et al. Neurosurgical treatment of Tourette's syndrome: a critical review. Compr Psychiatry 1995;36:141-56.

\section{ANSWERS}

1. F; 2. F; 3. T; 4. F; 5. T; 6. T; 7. F. 